\title{
Evaluation of the Efficacy of Ascorbic Acid in Prophylaxis of Induced Rhinovirus 44 Infection in Man
}

\author{
Andrew R. Schwartz, Yasushi Togo, \\ Richard B. Hornick, Suketami Tominaga, \\ and Richard A. Gleckman
}

\author{
From the Division of Infections Diseases, Department \\ of Medicine and the Division of Clinical \\ Investigation, Department of Social and Preventive \\ Medicine, University of Maryland School of Medicine, \\ Baltimore, Maryland; and the Infections Disease \\ Service, Lemuel Shattnck Hospital, \\ Boston, Massachusetts
}

\begin{abstract}
Twenty-one healthy, susceptible adult male volunteers were enrolled in a doubleblind study designed for evaluation of the prophylactic efficacy of ascorbic acid ( $3 \mathrm{~g}$ daily) in induced rhinovirus 44 infection of the upper respiratory tract. While in continuous isolation, 11 men received $1 \mathrm{~g}$ of ascorbic acid three times daily, and 10 men received a placebo for two weeks, after which an intranasal inoculum containing $100 \mathrm{TCID}_{50}$ of rhinovirus 44 was administered. Each man continued to receive the same dose of medication for one week after the viral challenge. All participants subsequently developed typical illness due to rhinovirus. Similar levels of antibody in serum, nasal washings, and sputum developed in all subjects. Nasal shedding of virus and the flow of the nasal mucociliary blanket were unaffected by the ingestion of ascorbic acid. No prophylactic benefit was demonstrated from the daily ingestion of $3 \mathrm{~g}$ of ascorbic acid in induced rhinovirus 44 infection in man.
\end{abstract}

Viral infections of the respiratory tract are the most common illness affecting mankind. The mortality from these afflictions is low, but the morbidity, when assessed as discomfort and time lost from gainful employment and leisure pursuits, is high. Therefore, it is critical to assess the controversial claims for the efficacy of ascorbic acid (vitamin $\mathrm{C}$ ) for the prevention and relief of colds.[1-5], The need for a further study of the possible role of ascorbic acid in the prophylaxis and therapy of viral infections of the respiratory tract under carefully controlled circumstances was evident.

The study reported here was designed to deternine whether an antiviral effect can be ascribed

Received for publication January 15, 1973, and in revised form April 30, 1973.

This work was supported by a grant from Hoffmann-La Roche, Inc., Nutley, New Jersey.

We thank the inmates and staff of the Maryland House of Correction, Jessup, Maryland for their cooperation in this study.

Please address requests for reprints to Dr. Andrew R. Schwartz, Division of Infectious Diseases, Hahnemann Medical College, 230 North Broad Street, Philadelphia, Pa. 19102. to ascorbic acid. A double-blind prophylactic evaluation of ascorbic acid was undertaken in susceptible volunteers with $^{1}$ induced rhinpvirus infections. A rhinovirus was selected because this is the most frequent cause of the common cold [6]. Previous experience with use of rhinovirus 44 to induce upper respiratory tract infections and the presence of a susceptible population led to the selection of this virus for the present study [7].

\section{Materials and Methods}

Participants. The participants were adult male inmates of the Maryland House of Correction, Jessup, Maryland, who after being informed of the purpose, methods, and hazards of the study, freely signed informed-consent forms. Only healthy individuals, who were free of detectable serum neutralizing antibody to rhinovirus 44, were admitted to the study. The participants ranged in age from 22 to 51 years (average age, 28 years). All participants were housed on one of the medical research wards where they were isolated from the. general prison population for a four-week period.

Design of the study. The observation period 
was divided into three segments. Initially there was one week of baseline observation. The second phase lasted two weeks, during which administration of the test medication was begun. Each man received two tablets from an individually coded bottle three times daily. These were either ascorbic acid $(500 \mathrm{mg})$ or a placebo. The total daily dose of ascorbic acid was $3 \mathrm{~g}$. This phase was used to observe the tolerance and possible toxicity of the test medication and to permit establishment of equilibrium at the high daily dose of ingested ascorbic acid. Additional physiologic and biochemical data were also obtained, and are subsequently described. The third phase of the study lasted one week and began after the intranasal instillation of a challenge pool of rhinovirus 44 . Each participant continued to receive the same dose of coded test medication during this final segment of the study. Subsequently, serial determinations of levels of antibody and tests for biochemical and physiologic parameters were continued for an additional 30 days on an outpatient basis.

Virologic materials and procedures. The rhinovirus 44 challenge pool and virologic materials and procedures used in the present study have been described [7]. Five-tenths milliliter of the second passage WI-38 rhinovirus was instilled in drops into each nostril on the day of challenge. Each man in both groups received a total of $100 \mathrm{TCID}_{50}$. Nasal washings were obtained for isolation of virus during the initial week of observation and daily after day -7 (day 0 is the day of the viral challenge). These samples were inoculated into WI-38-cell tube cultures. Titers of neutralizing antibody were determined in WI-38-cell tube cultures against $100 \mathrm{TCID}_{30}$ of rhinovirus 44. Specimens were collected on days $-2,7,14,21$, and 28 for titrations of antibody in serum, nasal washings, and sputum. All WI-38-cell tube cultures were rolled at $35 \mathrm{C}$. Samples of nasal washing and sputum were concentrated three to 10 times before the antibody assay. Titers of these samples were expressed as the titers in $10 \mathrm{mg}$ of IgA immunoglobulin.

Biochemical parameters. Serial observation of fasting blood sugar, blood urea nitrogen, creatinine, serum glutamic-oxalacetic transaminase, calcium, sodium, potassium, chloride, phosphorus, and carbon dioxide-combining power were made during all phases of the study. Complete blood counts, quantitative platelet counts, and urine analysis were also carried out by standard methods,

Determinations of ascorbic acid. Serial quantitative measurements of the fasting (morning) levels of ascorbic acid in plasma and the 24-hr urinary excretion of ascorbic acid were made for all three phases of the study. Plasma and acidified 24-hr urine samples were collected and treated with 3\% metaphosphoric acid and placed at $-70 \mathrm{C}$ until ascorbic acid assay was performed by the methods of Deutsch and Weeks [8].

Nasal mucociliary flow. Nasal mucociliary flow was studied in all participants by Dr. Yasuhito Sasaki and his associates of the Johns Hopkins University School of Medicine. A small $(<0.5 \mathrm{~mm}$ in diameter) spherical resin bead labeled with ${ }^{99} \mathrm{TcO}_{4^{-}}$was placed on the anterior nasal septal mucosa. The rate of movement of this particle was followed by serial polaroid exposures of the image on the oscilloscope of an Angar Camera, the collimeter of which was placed in contact with the patient's head $[9,10]$.

Clinical parameters. Clinical observations included objective evaluations of the following signs: rhinitis, pharyngitis, otitis, conjunctivitis, abnormal pulmonary findings, fever, and cervical lymphadenopathy. The symptoms evaluated included nasal discharge, nasal stuffiness, sore throat, ear ache, cough, sputum production, feverishness, headache, nausea, malaise, insomnia, vomiting, and diarrhea.

These symptoms and signs were individually scored on a scale of zero to three+ $(0$, not present; $1+$, mild; 2+, moderate; and 3+, severe). Ratings were made by the same observers who evaluated patients at the same time daily.

\section{Results}

Clinical findings. Eleven men received vita$\min \mathrm{C}$, and 10 men received the placebo. All participants developed a spectrum of various symptoms and signs compatible with rhinoviral illness. The onset of rhinitis, nasal discharge, nasal stuffiness, sore throat, and mild pharyngitis began in some men 12-24 hr after challenge and increased in frequency and severity with the addition of conjunctivitis, cough, and mild constitutional symptoms. These latter significant symptoms became maximal on the second and third 
days after challenge (figure 1). Following this nadir, the illness entered a resolution period; recovery was complete by the sixth or seventh day.

Daily comparisons showed that there were no significant differences in mean illness score, mean sign score, and mean symptom scores between the men given vitamin $\mathrm{C}$ and those given the placebo. The total scores were not significantly different between the two groups. The terminal increase in illness score in the group treated, with ascorbic acid was due to an exacerbation of typical rhiinoviral illness in one man that resolved over the subsequent $72 \mathrm{hr}$.

Consideration of the frequency and intensity of the individual signs and'symptoms reveals that on the fourth day after challenge nasal discharge, nasal stuffiness, and rhinitis were significantly less frequent among the recipients of vitamin $\mathrm{C}(\mathrm{P}<$ .01 , Fisher's exact test). It should be stated, however, that the peak illness among the recipients of vitamin $\mathrm{C}$ was reached one day earlier than in the groiip given placebo, and that the resolution process was more advanced on day 4 among the recipients of vitamin C. There is no statistically significant difference between these two groups on any other day "for any of the other signs and symptoms scored.

Nasal shedding of rhinovirus 44 was detected as early as $12 \mathrm{hr}$ after challenge and persisted, in a few men, for up to 10 days. The peak incidence of virus shedding was between days 2 and 6 (figure 2). There was no statistically significant

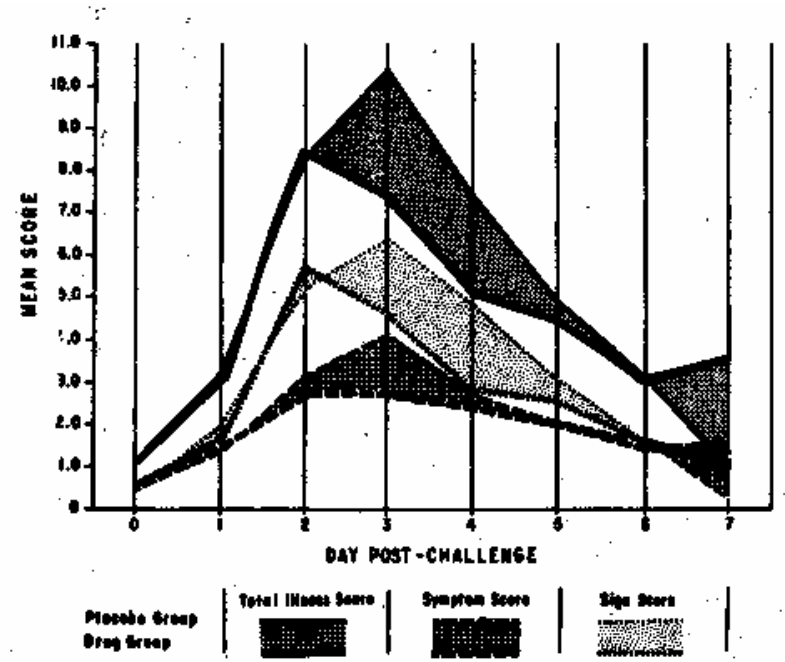

Figure 1. Daily mean scores of total illness, signs, and symptoms in men challenged.

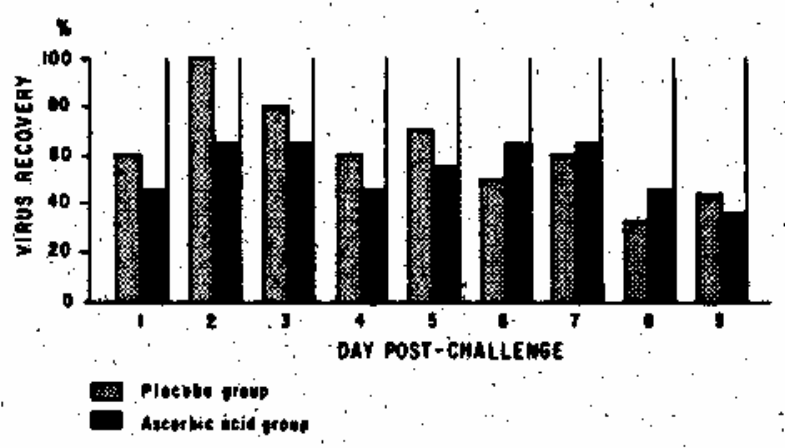

Figure 2. Daily nasal shedding of rhinovirus 44 by men treated with ascorbic acid ( $\square$ ) and placebo (중).

difference in the frequency of nasal virus shedding between the two groups. Rhinovirus 44 was isolated easily from the nasal washings of all participants during the course of the study.

The pattern of development of neutralizing antibody in serum is illustrated in figure 3. All participants developed at least a fourfold increase in neutralizing antibody in serum. Antibody began to rise after day 7 and was detectable on day 14; geometric mean titers (GMTs) were 1:26.9 in the placebo group and 1:26.4 in the vitamin $\mathrm{C}$ group. These titers continued to rise until day 21 and remained elevated a,t the end of four weeks, with GMTs of 1:64.0 in the placebo group and 1:68.5 in the recipients of vitamin C. No significant differences were noted between the placebo and vitamin $\mathrm{C}$ groups as to the magnitude or the pattern of evolution or distribution of titers of neutralizing antibody to rhinovirus 44 in serum.

The levels of nasal secretory antibody were noted initially to be elevated by the seventh day after challenge in both groups (figure 4). The titers continued to rise, and at the end of four weeks the GMT of 1:6.5 for the placebo group was not significantly different from the GMT of 1:5.0 among the recipients of ascorbic acid. Neutralizing antibody in sputum was also detected as early as day 7 (figure 4). These levels increased over the next two weeks and then fell toward the end of the fourth week. Both groups had GMTs of 1:3.5 on day 38. No significant differences in antibody titers were found between the two groups.

Among, the clinical laboratory parameters monitored throughout the study, ho clinically meaningful abnormalities were observed; and 


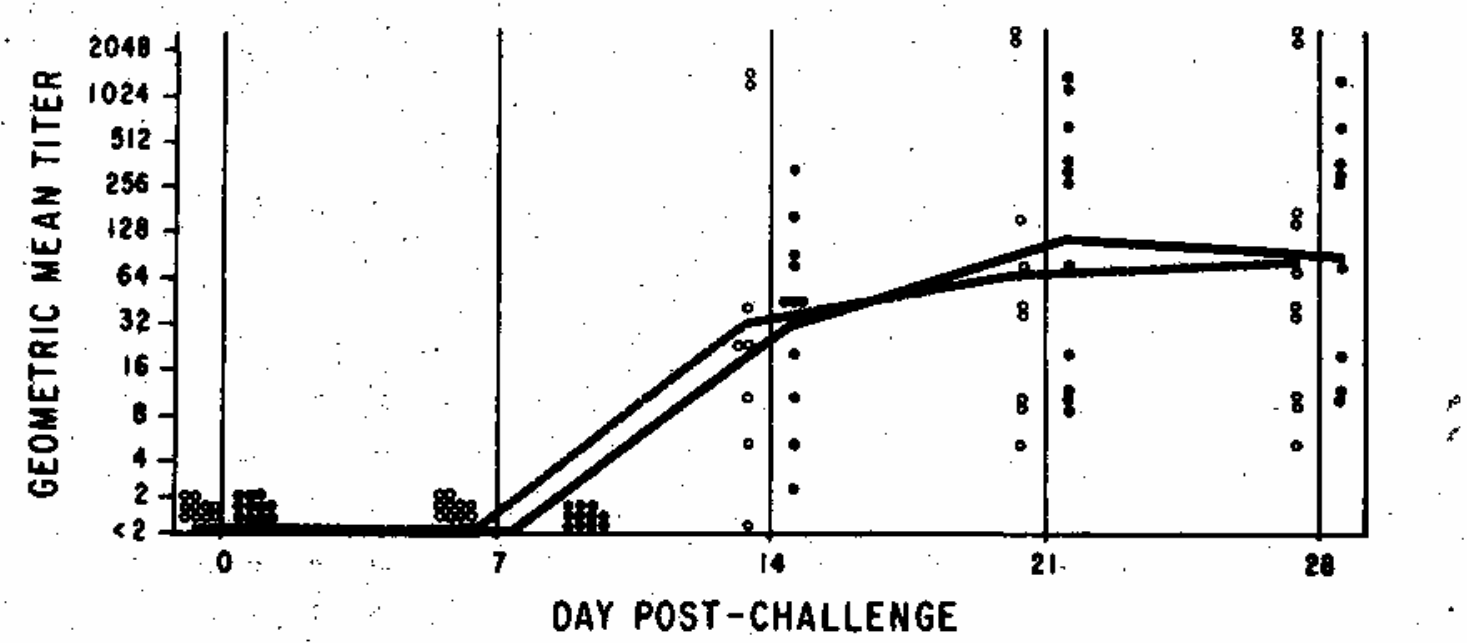

Figure 3. Serum neutralizing antibody to rhinovirus 44 in recipients of vitamin $C(-\longrightarrow)$ and in those who received placebo (- - ),

neither group differed significantly from their baseline values.

Levels of ascorbic acid. Fasting (morning) levels of ascorbic acid in plasma were determined during the baseline period (day -16), after 12 days of medication (day - 2), two and six days after challenge (while medication was still being taken), and 21 days after challenge (two weeks after medication was stopped). These data are shown in table 1.

During the period of irigestion of vitamin C, the levels of ascorbic acid in plasma rose slightly and reached a plateau, with a concomitant marked increase in the urinary excretion of ascorbic acid. The differences in fasting levels of ascorbic acid in plasma between the recipients of vitamin $\mathrm{C}$ and the controls were further accentuated by the expected fall in ascorbic acid in plasma accompanying the onset of infection.

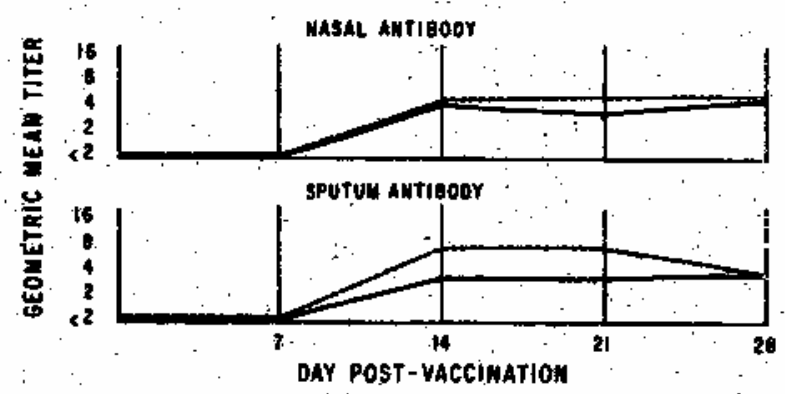

Figure 4. Neutralizing antibody to rhinovirus 44 in nasal washings and sputa of men who received vitamin $\mathrm{C}(\longrightarrow)$ and placebo-treated controls $(---)$..
There was little day-to-day variation in the cqncentration of ascorbic acid in the plasma of any one individual within one treatment group.

Nasal mucociliary flow. The nasal mucociliary clearance of minute tagged particles was not significantly affected by the ingestion of ascorbic acid. The rate of mucociliary flow was similarly reduced in both groups after viral challenge and returned to normal at the same rate after recovery from illness.

Tolerance and toxicity. There were no adverse reactions that could be directly attributed to therapy with a drug or placebo. Specifically, headache, insomnia, anorexia, nausea, vomiting, and diarrhea were not observed among the partici pants in this study.

\section{Discussion}

The present study used a screened, healthy population serologically proved to be susceptible and challenged them with a single virus, rhinovirus 44 , in a uniform, moderate quantity, delivered to the nasal epithelium. This approach has eliminated some of the variables that occur with naturally-acquired colds, where a variety of unknown viruses of differing virulence and quantity are involved. Trained personnel have insured that the medication was taken as prescribed. The objective parameters studied were observed and evaluated uniformly by the same individuals lising the same methods, standards, and equipment. This standardized approach has enabled us to 
Table 1. Concentrations of ascorbic acid in plasma and urine of adult men given ascorbic acid ( $3 \mathrm{~g}$ daily) and of controls given placebo before and after challenge with rhinovirus 44 .

\begin{tabular}{|c|c|c|c|c|c|}
\hline \multirow{2}{*}{ Ascorbic acid } & \multicolumn{2}{|c|}{$\cdot \quad \vdots \quad$} & Day of study & \multicolumn{2}{|l|}{. } \\
\hline & -16 & -2 & $\therefore$ & 6 & 21 \\
\hline \multicolumn{6}{|l|}{ Plasma $(\mathrm{mg} / 100 \mathrm{ml})$} \\
\hline $\begin{array}{l}\text { Ascorbic acid group } \\
\text { Placebo group } \\
P^{\dagger}\end{array}$ & $\begin{array}{l}1.06 \pm 0.16^{*} \\
0.76 \pm 0.20 \\
\quad 0.245\end{array}$ & $\begin{array}{l}1.48 \pm 0.12 \\
0.59 \pm 0.11 \\
0.000(08) \ddagger\end{array}$ & $\begin{array}{c}0.91 \pm 0.10 \\
0.47 \pm 0.12 \\
0.012\end{array}$ & $\begin{array}{c}1.10 \pm 0.11 \\
0.60 \pm 0.14 \\
0.011\end{array}$ & $\begin{array}{c}0.83 \pm 0.10 \\
0.70 \pm 0.15 \\
0.478\end{array}$ \\
\hline \multicolumn{6}{|l|}{ Urine (mg/day) } \\
\hline $\begin{array}{l}\text { Ascorbic acid group } \\
\text { Placebo group } \\
\boldsymbol{P}\end{array}$ & $\begin{array}{c}53.67 \pm 26.05 \\
76.55 \pm 36.55 \\
0.630\end{array}$ & $\begin{array}{c}850.00 \pm 125.55 \\
54.09 \pm 27.45 \\
0.000(08)\end{array}$ & $\begin{array}{c}1069.91 \pm 152.02 \\
18.20 \pm 6.77 \\
0.000(09)^{6}\end{array}$ & $\begin{array}{c}911.73 \pm 118.61 \\
26.60 \pm 10: 31 \\
\cdots 0.000(09)\end{array}$ & $\begin{array}{c}20.00 \pm 5.92 \\
16.27 \pm 5.25 \\
0.686\end{array}$ \\
\hline
\end{tabular}

Note. Ascorbic acid and placebo tablets were administered from day -13 through day 7 .

* Data presented as mean $\pm S E$.

† Student's t test.

$\therefore$ \$ Numbers in parentheses indicate calculations carried out to further decimal places.

study a small population. Previous studies of the efficacy of vitamin $C$ have varied in some of the parameters evaluated, populations studied, and the immune status of those participating [11-14]. These have recently been reviewed [15]. The only other controlled study using comparable doses of vitamin $C$, in screened healthy adult-volunteers challenged with rhinoviruses and type $\mathrm{B}$ influenza virus failed to reveal any effect of vitamin $C$ on the course, duration of symptoms, number of the colds induced, or the magnitude of virus shedding [14].

The dose of ascorbic acid administered ( $3 \mathrm{~g}$ daily) is larger than that used by others. The two-week period of drug administration was provided before challenge for physiologic observations, evaluation of tolerance of the patients, and saturation of tissues with ascorbic acid. The ingestion of large daily doses of vitamin $\mathrm{C}$ leads to saturation of tissues and a constant fasting (morning) plasma level, which is not significantly different from that of individuals whose normal dietary intake of ascorbic acid is far lower. Elevated urinary excretion accompanies the oral ingestion of excess vitamin $\mathrm{C}$

As noted above, all participants developed signs and symptoms compatible with rhinoviral illness after intranasal administration of rhinovirus 44 . The differences in the day of peak illness and the magnitude of the mean illness, sign, and symptom scores are not statistically significant between the two groups. The differences noted on day 4 in the subjective symptoms of nasal discharge and nasal stuffiness and the sign, rhinitis, are probably related to the slightly earlier peak of illness among the vitamin $\mathrm{C}$ recipients. It is clear that the clinical course of the rhinoviral infection was neither prevented nor significantly ameliorated by the ingestion of $1 \mathrm{~g}$ of vitamin $\mathrm{C}$ taken three times daily.

This conclusion is further corroborated when consideration is given to the evaluation of the other more objective parameters studied. Nasal shedding of virus was equivalent in both groups, confirming that rhino virus 44 was able to invade and multiply in the cells of the nasal mucosa without significant inhibition by either ascorbic acid or placebo. The pattern of development and magnitude of neutralizing antibody in serum and of antibodies in nasal washings and sputum were similar in both groups. This further substantiates that the antigenic exposure and responses of the susceptible hosts in both groups were comparable. If vitamin $\mathrm{C}$ were effective in increasing resistance of the host to infections of the upper respiratory tractj it could act by interfering with or modifying one of the stages in the sequence of events following exposure to a cold virus. It might diminish viral penetration of the nasal epithelial cells, or reduce the ability of the virus to replicate within these cells, or impair the spread of the released virus to adjacent, noninfected cells. In view of the experience cited above with induced rhinovirus 44 infection, there appears to be no evidence that any of these stages of infection have been altered by the administration of vitamin $\mathrm{C}$.

Depression of nasal mucociliary flow in response to inflammation of the respiratory tract 
has been reported [9], If ascorbic acid affected this process, it would be expected that the anticipated decrease in the mucous blanket flow after infection would be altered. The identical impairment of flow of the nasal mucosal mucus blanket in both test groups again confirms that ascorbic acid has no demonstrable efficacy.

Another possible mechanism might be through the stimulation of interferon production. Other studies have failed to demonstrate either enhancement or inhibition of induced interferon responses, in vitro or in vivo, in scorbutic tissues and animals or under conditions of augmented vitamin C ([16] and D, P. Plantarose and L, Smith, personal communication).

In this experimental model the daily administration of $3 \mathrm{~g}$ of vitamin $\mathrm{C}$ was not associated with any demonstrable prophylactic effect against induced rhinovirus 44 infection in susceptible adult male volunteers.

\section{References}

1. Pauling, L. C. Vitamin $\mathrm{C}$ and the common cold. W. H. Freeman, San Francisco, 1970. 122 p.

2. Lee, R. V. Shaking up the doctors. Nutrition Today 6:16-17, 1971 .

3. Passmore, R. New nostrum. Nutrition Today 6:1718, 1971.

4. Stare, F. J. Not quite cricket. Nutrition Today 6:18-20, 1971.

5. Regnier, E. The administration of large doses of ascorbic acid in the prevention and treatment of the common cold. Rev. Allerg. 22:835-846, 946$948,1968$.
6. Hamre, D., Connelly, A. P., Jr., Procknow, J. J. Virologic studies of acute respiratory disease in young adults, IV. Virus isolations during four years of surveillance/Am. J. Epidemiol. 83:238249, 1966.

7. Togo, Y., Schwartz, A, R., Hornick, R. B. Failure of a 3-substituted triazinoindole in the prevention of experimental rhinovirus infection. Chemotherapy 18:17-26, 1973.

8. Deutsch, M. J., Weeks, C. E. Microfluorometric assay for vitamin C. J. Assoc. Official Agricultural Chemists 48:1248-1256, 1965.

9. Proctor, D. F. Measurement of mucociliary activirin man. Ann. Otol. Rhinol. Laryngol. 78:518531, 1969.

10. Quinlan, M. F., Salman, S. D., Swift, D. L., Wagner, H. N., Jr., Proctor, D. F. Measurement of mucociliary function in man. Am. Rev. Resp. Dis. 99:13-23, 1969.

11. Cowan, D. W., Diehl, H. S., Baker, A. B, Vitamins for the prevention of colds. J.A.M.A. 120:12681271, 1942.

12. Cowan, D. W., Diehl, H. S. Antihistamtnic agents and ascorbic acid in the early treatment of the common cold. J.A.M.A. 143:421-424, 1950.

13. Ritzel, V. G. Kritische Beuteilung des Vitamins C als Prophylacticum und Therapeuticum der Erkaltungskrankheiten. Helv. Med. Acta 28:6368, 1961.

14. Walker, G. H., Bynoe, M. D., Tyrrell, D. A. J. Trial of ascorbic acid in prevention of colds. Br. Med. J. 1:603-606, 1967.

15. Hornick, R. B. Does ascorbic acid have value in combatting the common cold? Medical Counterpoint 4:15, 50-56, 1972.

16. Versteeg, J. Effect of ascorbic acid on virus replication and production and activity of interferon in vitro. Proc. Kon. Nederl. Akad. Wet. (Biol. Med.) 72:207-212, 1969. 